\title{
Strategy to design DNA-biosensors: Single-stranded probe grafting versus target-probe duplex grafting
}

\author{
C. Védrine ${ }^{a}, M$. Lazerges $^{b, c, *}, H$. Perrot ${ }^{b, c}, C$. Compère ${ }^{d}, C$. Pernelle ${ }^{a}$ \\ ${ }^{a}$ CNAM, LC3B, Laboratoire Conception Capteurs Chimiques et Biocapteurs, 292 rue Saint-Martin, 75141 Paris, \\ Cedex 03, France \\ ${ }^{\mathrm{b}}$ CNRS, UPR 15, Laboratoire Interfaces et Systèmes Electrochimiques, 4 place Jussieu, 75252 Paris, France \\ ${ }^{c}$ Université Pierre et Marie Curie, LISE, 4 place Jussieu, 75252 Paris, France \\ d IFREMER, Centre de Brest, Service Interfaces et Capteurs, Z.I. pointe du diable, 29280 Plouzané, France \\ *: Corresponding author : M. Lazerges, email address : mathieu.lazerges@univ-paris5.fr
}

\begin{abstract}
:
A strategy to design DNA-biosensors by grafting probe-target duplex onto a $27 \mathrm{MHz}$ quartz crystal microbalance gold surface is presented in this work. The idea that removing the DNA target after duplex grafting yields to a well accessible probe, and therefore to efficient target recognition, is investigated. Unfortunately, hybridization efficiency measured using such a straightaway protocol is equal to $15 \%$, which is feeble by comparison with the $31 \%$ hybridization efficiency measured for biosensors designed with single-stranded probe. Successive DNA biosensors are designed in this work, taking into account phenomena that occur specifically in an interfacial environment, like non specific adsorption or exchange reactions between adsorbed molecules. A DNA-biosensor with an optimized biolayer in terms of probe accessibility and probe surface density is in fine designed: a $59 \%$ hybridization efficiency, for a complementary target including a 20-base non complementary sequence oriented toward the surface, is obtained for the biosensor designed with target-probe duplex. This hybridization efficiency is 3 times to $18 \%$ measured for biosensors designed with single-stranded probe.
\end{abstract}

Keywords : Alexandrium minutum ; Biosensor ; Double-stranded DNA ; Quartz crystal microbalance 


\section{Introduction}

First work on biosensors designed using double-stranded DNA report a 45\% hybridization ratio for a perfect match DNA target [1]. This hybridization ratio is close to the efficiency of biosensors designed by grafting single stranded DNA, equal to $47 \%$ [2] and $44 \%$ [3], but is far below efficiency of DNA biosensors designed by grafting single stranded DNA and using an hydrophilic spacer, equal to $95 \%$ [4] and $68 \%$ [5]. We demonstrate that a $92 \%$ hybridization efficiency can be reached using non complementary disulfide-labelled single standed DNA as an hydrophilic spacer [6]. Recent work on biosensors designed by grafting double-stranded DNA in a two-step grafting scheme with using hydrophilic spacer reports a $88 \%$ hybridization efficiency for a perfect complementary DNA [7]. All previous studies on biosensors designed using ds-DNA deal with optimization of the biolayer design for the detection of a perfect complementary DNA target, but the question on hybridization efficiency decrease when DNA target includes a non complementary sequence oriented toward the surface is poorly adresed. This last case is specially interesting as it is relevant to biological DNA targets (RNA, PCR amplified DNA and genomic DNA). We demonstrate in a recent study that both perfect complementary and complementary large DNA target including a non complementary sequence oriented toward biosensor surface can be detected using a one-step grafting scheme, yielding respectively to $80 \%$ and $53 \%$ hybridization efficiency [5]. These results indicate that biosensors designed using a double-stranded DNA are especially interesting in the case of large DNA targets detection, which include large non complementary sequences, like real DNA samples coming from cell extraction or polymerase chain reaction. A detailed strategy to design DNA-biosensors using double-stranded DNA is presented in this work. A preliminary part is consecrated to investigation of limits of biosensor recognition designed with single-stranded probes. The second part deals with different strategies to design biosensors using double-stranded DNA, from the simplest and straightest protocol, consisting of direct duplex grafting, yielding to a poor hybridization efficiency, to a multi-step advanced procedure taking into accounts interfacial constraints and yielding to high hybridization efficiency.

\section{Experimental}

\subsection{Chemical and biochemical reagents}

Water is deionized and double distilled. $\mathrm{H}_{2} \mathrm{SO}_{4} 95 \%, \mathrm{H}_{2} \mathrm{O}_{2} \quad 30 \%$, 2-mercapto-1-ethanol $\left(\mathrm{HSCH}_{2} \mathrm{CH}_{2} \mathrm{OH}\right), \mathrm{NaOH}, \mathrm{HCl}, \mathrm{NaCl}, 1 \mathrm{M}$ HEPES buffer are from Sigma Aldrich (biochemical grade). DNA strands from Eurogentec [8] are purified by chromatography, 
checked by MALDI-TOF analysis and dosed by UV optical density measurements. Sequences of thiol- and disulfide- labeled DNA probes (P1 and P1'), non complementary random DNA (R) and complementary DNA targets (T1 to T6) are: 3'-TCGGG AATGT GTAGT CACGA AGCAC TGATG TGTAA GGGCT-5'-C6-thiol (P1), 3'-TCGGG AATGT GTAGT CACGA AGCAC TGATG TGTAA GGGCT-5'-C6-disulfide (P1'), 3'-CCTTG GTCTG TGTTT CAAGA-5' (R), 3'-TCGTG ACTAC ACTAC CCCGA-5' (T1), 3'-ACTAC CCCGA-5' (T2), 3'-ACTAC ACTAC-5' (T3), 3'-TCGTG ACTAC-5' (T4), 3'-TCGTG ACTAC ACTAC CCCGA R-5' (T5), 3'-R TCGTG ACTAC ACTAC CCCGA-5' (T6). The sequence of the DNA probes ( $\mathrm{P} 1$ and $\mathrm{P} 1 ')$ is a partial sequence of the gene encoding for the large ribosomal RNA sub-unit of Alexandrium minutum [9,10,11], a toxic algae responsible of paralytic shellfish poisoning [12] on American, Asian and European coasts [13,14,15].

\subsection{Buffers and solutions}

Probe grafting is performed in saline solution (3.2 $\mu \mathrm{M}$ DNA-probe, $0.5 \mathrm{M} \mathrm{NaCl}$ ). Hybridization runs are performed in saline solution (1.6 $\mu \mathrm{M}$ DNA-target, $0.5 \mathrm{M} \mathrm{NaCl})$ or in optimized saline buffer (1.6 $\mu \mathrm{M}$ DNA-target, 0.05 M HEPES, $0.5 \mathrm{M} \mathrm{NaCl}$, adjusted to $\mathrm{pH} 7.2$ with $1 \mathrm{M} \mathrm{NaOH})$ [2]. Regeneration is performed using an alkaline saline solution $(0.5 \mathrm{M}$ $\mathrm{NaOH}, 3 \mathrm{M} \mathrm{NaCl}$ ). The blocking reagent solution used to avoid non specific adsorption of DNA strands on gold surface is a 2-mercapto-1-ethanol solution $\left(10^{-3} \mathrm{M}\right)$.

\subsection{Preparation of double stranded DNA solution}

Double stranded DNA solution is prepared by mixing solutions of $\mathrm{P} 1$ probe $(1.6 \mu \mathrm{M})$ and T5 target $(3.2 \mu \mathrm{M})$ in $\mathrm{NaCl}(0.5 \mathrm{M}) 30$ minutes before grafting step. The excess of target ensures that all probes are hybridized.

\subsection{Quartz crystal microbalance}

The resonator of the microbalance is a Matel-Fordhal France AT-cut planar quartz crystal, 14 $\mathrm{mm}$ in diameter, with a $9 \mathrm{MHz}$ nominal resonance frequency. Two identical gold electrodes, $2000 \AA$ thick, with a $250 \AA$ chromium underlayer and $5 \mathrm{~mm}$ in diameter, are deposited by evaporation techniques on both sides of piezoelectric quartz. The resonator is connected by a silver conducting paste, through wires, to a BNC connector. A lab-made oscillator is designed to drive the crystal at $27 \mathrm{MHz}$, which corresponds to the third overtone of the quartz 
resonator, with low noise signals [16]. To improve the stability, all the electronic oscillator components are temperature-controlled by a Watlow heater monitor with stability better than $0.1{ }^{\circ} \mathrm{C}$. The crystal is mounted between two O-ring seals inserted in a home-made Plexiglass cell. One face of the quartz is in contact with the solutions. The cell volume is $50 \mu \mathrm{L}$. The apparatus includes a Pharmacia micropump to assure a $50 \mu \mathrm{L} / \mathrm{min}$ constant flow of the solutions in the quartz cell. The frequency is measured with a PM 6685 frequency counter and recorded with a home-made $\mathrm{C}$ language software. The experiments are performed at $25 \pm 2$ ${ }^{\circ} \mathrm{C}$.

\section{Biosensor designed by grafting single stranded DNA probe}

\subsection{Probe grafting, target hybridization and biosensor regeneration}

Two biosensors are designed by grafting respectively thiol-labeled probe P1 and disulfidelabeled probe $\mathrm{P} 1$ ' on the gold which covers the quartz surface of the microbalance. Frequency-time grafting and hybridization curves of biosensors designed with thiol-labeled probe P1 (Fig. 1-A) and disulfide- labeled probe P1' (Fig 1-B) are performed.
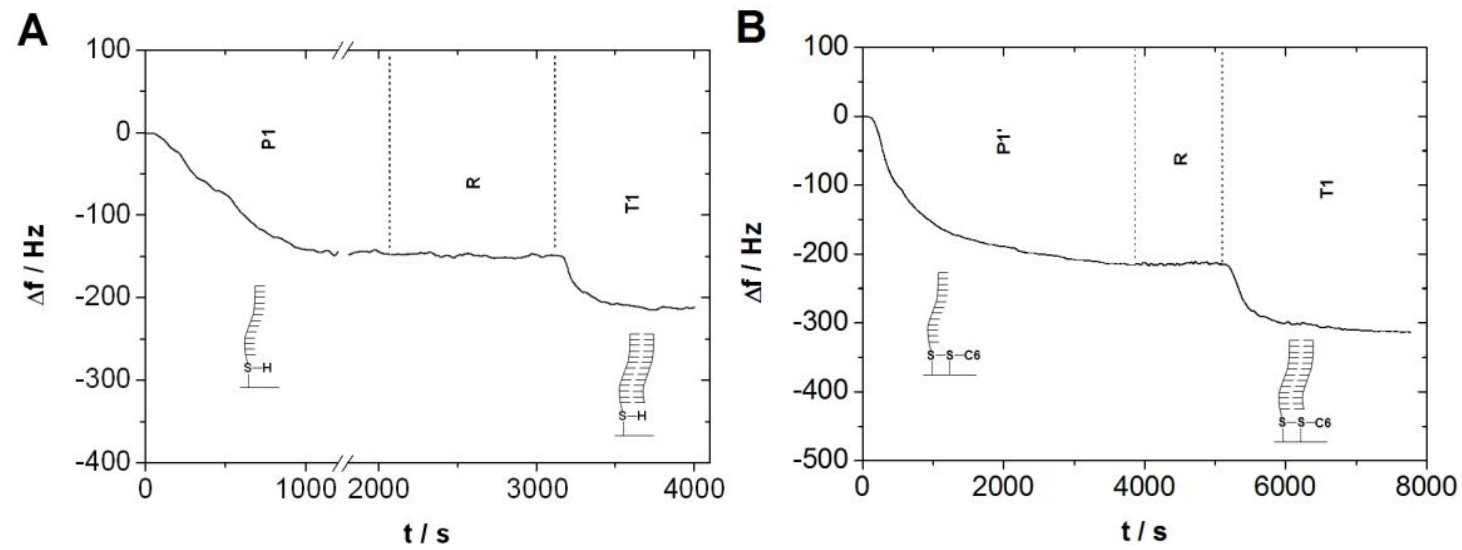

Fig 1. Frequency-time curves of thiol-labeled probe P1 (A) and disulfide-labeled P'1 (B) grafting, random DNA R solution circulation, and complementary target T1 hybridization.

A microbalance frequency decrease is recorded during probe P1 grafting in saline solution (3.2 $\mu \mathrm{M}, \mathrm{NaCl} 0.5 \mathrm{M}$ ). The biosensor probe surface density $\Gamma$ estimated is equal to $2.4 .10^{13}$ probe $/ \mathrm{cm}^{2}$.

$$
\Gamma=\left|\Delta \mathrm{f}_{\mathrm{P} 1}\right| \cdot \mathrm{S}_{\mathrm{QCM}} \cdot \mathrm{N}_{\mathrm{A}} / \mathrm{A}_{\mathrm{QCM}} \cdot \mathrm{M}_{\mathrm{P} 1}[1]
$$


$\Delta \mathrm{f}_{\mathrm{P} 1}$ is the frequency change during probe grafting $(-141 \mathrm{~Hz}), \mathrm{S}_{\mathrm{QCM}}$ the experimental microbalance sensitivity coefficient $(350 \mathrm{pg} / \mathrm{Hz})[17], \mathrm{N}_{\mathrm{A}}$ the Avogadro constant $\left(6.023 .10^{23}\right.$ $\left.\mathrm{mol}^{-1}\right), \mathrm{A}_{\mathrm{QCM}}$ the gold covered quartz detection geometric surface $\left(0.2 \mathrm{~cm}^{2}\right)$ and $\mathrm{M}_{\mathrm{P} 1}$ the probe molecular weight $(6337 \mathrm{~g} / \mathrm{mol})$. There is no frequency shift during circulation of a non complementary R strand solution, indicating that no non specific physical adsorption occurs. A microbalance frequency decrease is recorded during circulation of a complementary target T1 solution (3.2 $\mu \mathrm{M}, \mathrm{NaCl} 0.5 \mathrm{M}, \mathrm{pH} 7.2)$, indicating successful hybridization of the target with a complementary grafted probe. The hybridization efficiency $\eta(\%)$ is:

$$
\eta=100 \cdot \Delta \mathrm{f}_{\mathrm{T} 1} \cdot \mathrm{M}_{\mathrm{P} 1} / \Delta \mathrm{f}_{\mathrm{P} 1} \cdot \mathrm{M}_{\mathrm{T} 1}[2]
$$

$\Delta \mathrm{f}_{\mathrm{T} 1}$ is the microbalance frequency change during hybridization $(-58 \mathrm{~Hz})$ and $\mathrm{M}_{\mathrm{T} 1}$ the target T1 molecular weight $(6055 \mathrm{~g} / \mathrm{mol})$. The hybridization efficiency calculated is equal to $43 \%$. For the disulfide-labeled probe P1', coverage surface and hybridization efficiency are are respectively equal to $3.6 .10^{13}$ probe $/ \mathrm{cm}^{2}$ and $42 \%$, calculated with equations [1] and [2], taking into account the frequency change $\Delta \mathrm{f}_{\mathrm{P} 1^{\prime}}$ during probe grafting $(-216 \mathrm{~Hz})$, the frequency change $\Delta \mathrm{f}_{\mathrm{T} 1}$ during target $\mathrm{T} 1$ hybridization $(-87 \mathrm{~Hz})$ and probe $\mathrm{P} 1$ ' molecular weight $\mathrm{M}_{\mathrm{P} 1}$ $(6354 \mathrm{~g} / \mathrm{mol})$. Probe surface densities are equal to $2.3 .10^{13} \mathrm{probe} / \mathrm{cm}^{2}\left(4.3 \mathrm{~nm}^{2} /\right.$ probe $)$ for the biosensor designed with the thiol-labeled probe $\mathrm{P} 1$ and to $3.6 .10^{13} \mathrm{probe} / \mathrm{cm}^{2}\left(2.7 \mathrm{~nm}^{2} / \mathrm{probe}\right)$ for the one designed with the disulfide-labeled probe P1'. The surface per probe measured are different and higher than those of $2.2 \mathrm{~nm}^{2}$ reported [2], but as it was show elsewhere, molecule adsorption process depend on surface roughness [18], and yields in the case of gold quartz surface to different frequency shifts [6]. Nevertheless, the hybridization efficiencies, equal to $43 \%$ for the biosensor designed with the thiol-labeled probe P1 and equal to $42 \%$ for the biosensor designed with the disulfide-labeled probe P1', are close, indicating that selfassembled monolayers of thiol- and disulfide- labeled probes onto gold surface have the same hybridization properties. Hybridization ratio rather than probe surface density will be used to evaluate efficiency of biosensors designed in this study, as this value does not depend on the commercial quartz used. These biosensors can be regenerated by circulation of an alkaline saline solution ( $\mathrm{NaOH} 0.5 \mathrm{M}, \mathrm{NaCl} 3 \mathrm{M}$ ) during 30 minutes. $\mathrm{P} 1$ probe grafting and successive hybridization runs are performed (Fig. 2). Microbalance frequency shifts during P1 probe grafting is equal to $-225 \mathrm{~Hz}\left(3.7 .10^{13}\right.$ probe $\left./ \mathrm{cm}^{2}\right)$. 


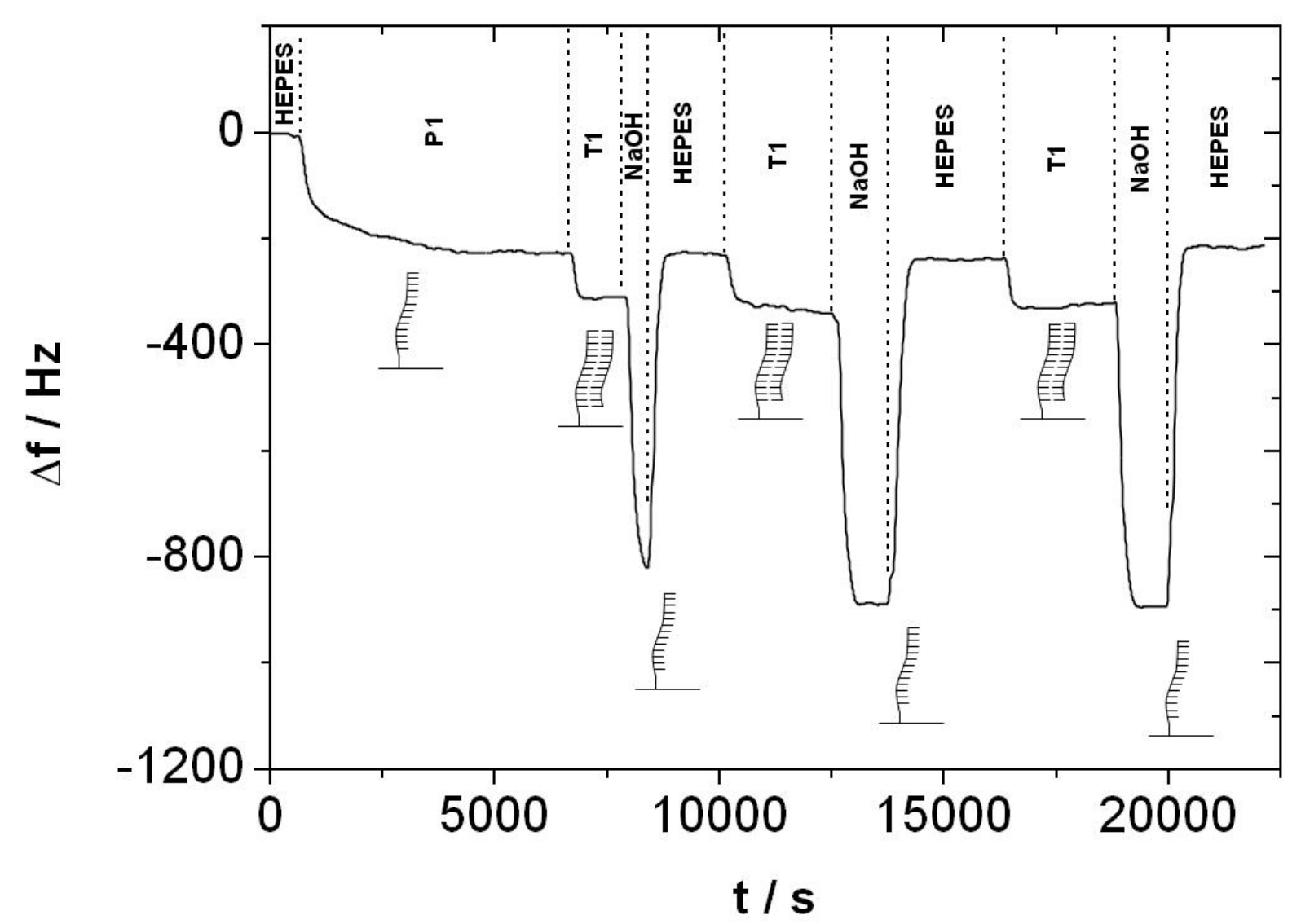

Fig. 2. Frequency-time curves of thiol-labeled probe P1 grafting and successive hybridizationregeneration runs of the complementary 20 -base target $\mathrm{T} 1$.

Drastical frequeny decrease during $\mathrm{NaOH}$ flow is due to important increase of solution density and conductivity, such a phenomenum was already observed for this kind of accoustic sensor [6]. Microbalance frequency shifts measured for the three successive hybridization runs are $-85,-93$ and $-92 \mathrm{~Hz}$. Hybridization efficiencies are equal to 40, 44 and $43 \%$. These results indicate that successive hybridization runs can be performed on the same biosensor without any significant signal loss. This property will be used to measure hybridization efficiency of different targets on the same biosensor.

\subsection{Effects of steric hindrance on hybridization efficiency}

A DNA-biosensor is designed with disulfide-probe P1' $\left(3.4 .10^{13}\right.$ probe $\left./ \mathrm{cm}^{2}\right)$. Hybridization of two 40-base targets including a 20-base sequence complementary to the probe, and a 20-base non complementary sequence oriented toward 3' (T6) and oriented toward 5' (T5) are performed (Fig. 3). 


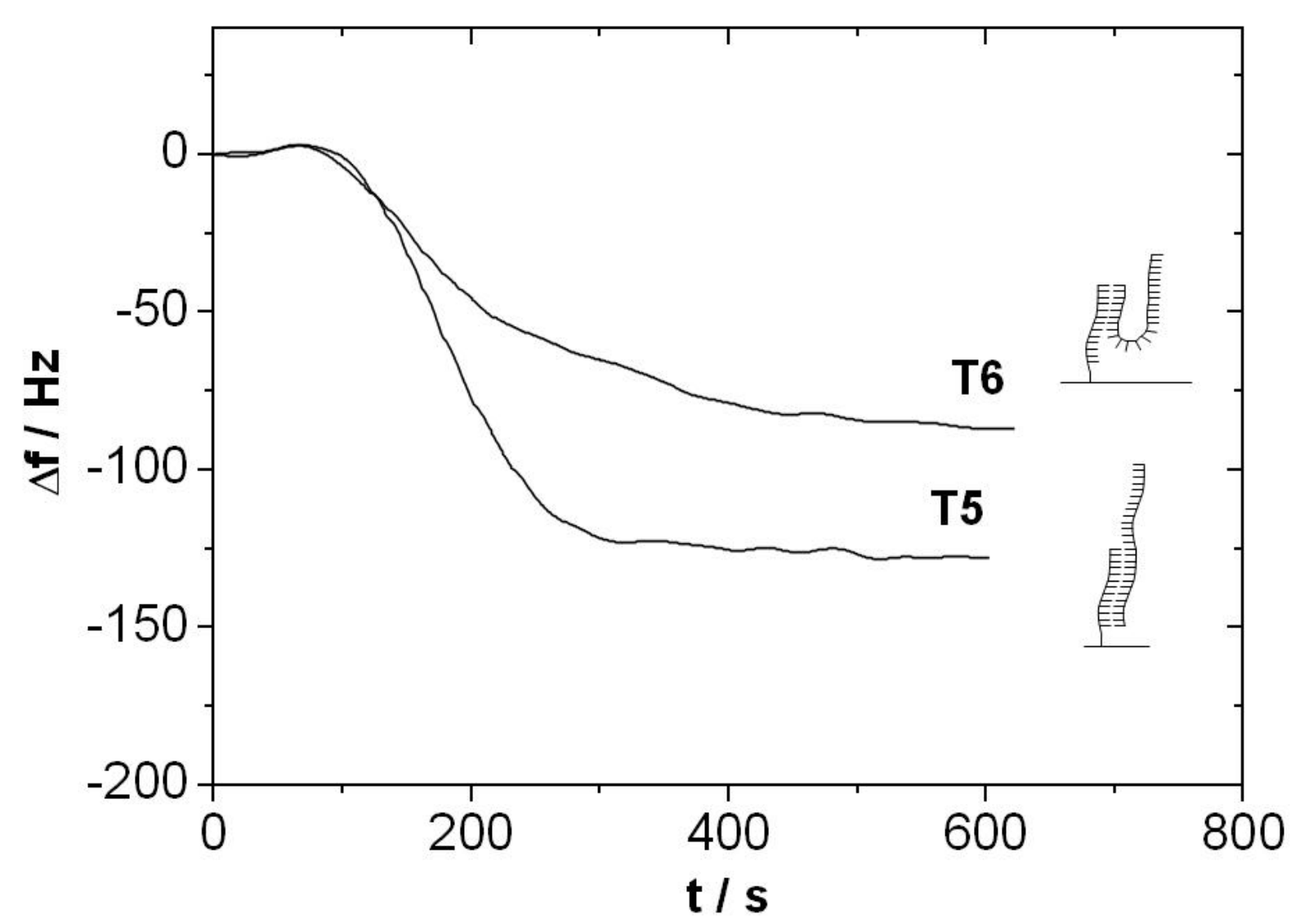

Fig. 3. Frequency-time hybridization curves of T5 and T6 40-base complementary targets.

Hybridization efficiencies of T5 and T6 targets are respectively equal to 29 and $19 \%$. The difference between hybridization efficiencies of these two targets can be explained by the geometry of the duplex formed on the biosensor surface. In the case of T5 target, the 20-base non complementary sequence of the target is oriented toward the solution. In the case of T6 target, the 20-base non complementary sequence of the target is oriented toward the surface, where repulsion with other grafted and hybridized nucleic acids are more important (Fig. 3). These results indicate that hybridization on a self-assembled probe monolayer depends on the position of the complementary sequence on the target. Hybridization of three 10-base targets, complementary to a 10-base probe sequence of the probe located on 3 ' probe extremity (T2), on the probe center (T3) and on the 5' probe extremity (T4), are performed (Fig. 4). 


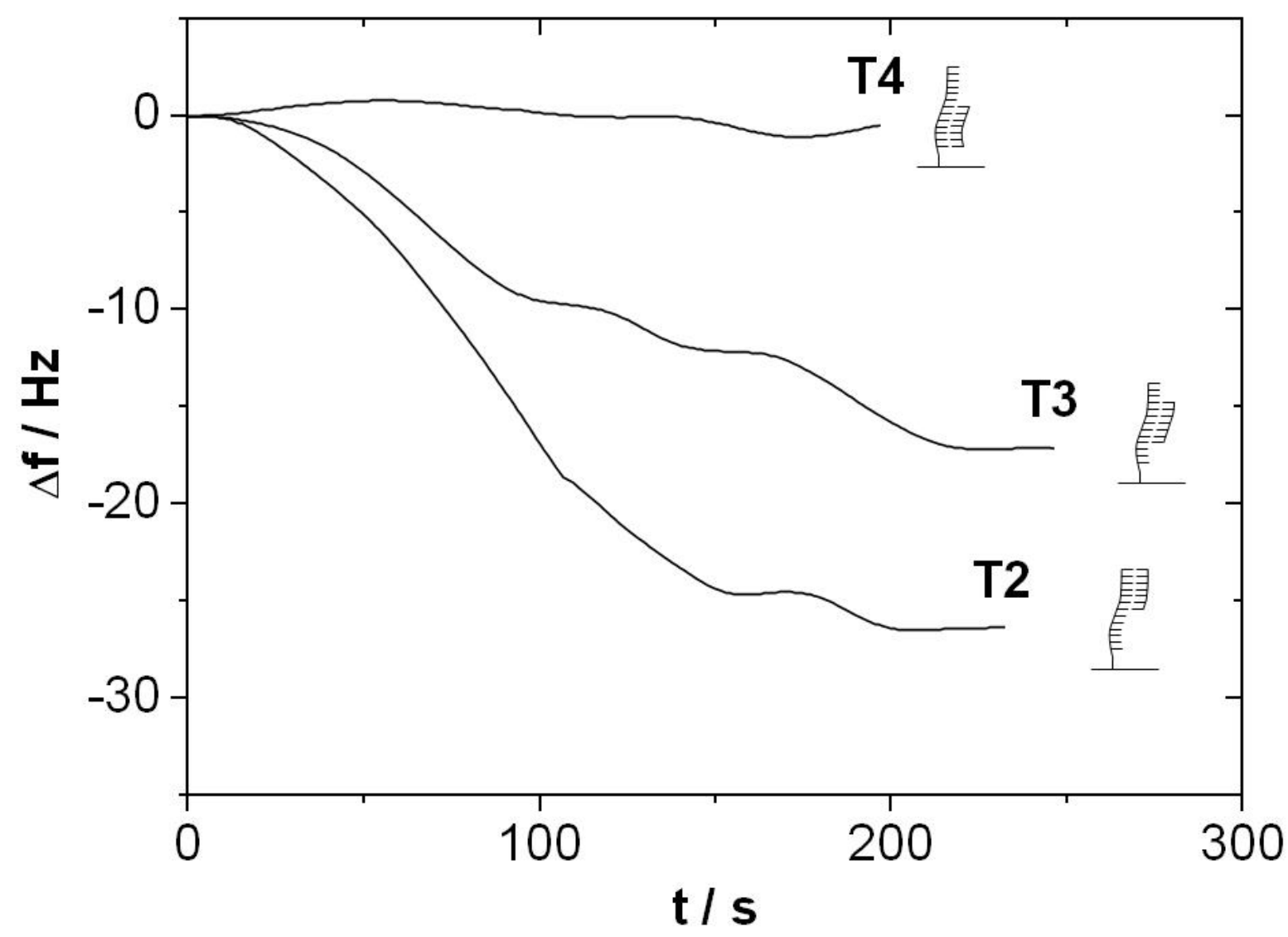

Fig. 4. Frequency-time hybridization curves of $\mathrm{T} 2$, $\mathrm{T} 3$ and $\mathrm{T} 4$ 10-base complementary targets.

Hybridization efficiencies of T2, T3 and T4 targets are respectively equal to 26,17 and $1 \%$. The difference between hybridization efficiencies for these three targets can be explained by the geometry of the duplex formed on the biosensor surface: in the case of T2 target, the 10base hybridized probe sequence is located close to the solution, and in the case of T4 target, the 10-base hybridized probe sequence is located close to the surface, where repulsion with other grafted and hybridized nucleic acids and steric hindrances are more important. Successive hybridizations runs of complementary DNA targets T1 to T6 are reproducible (Table 1).

\begin{tabular}{c|cccccc} 
DNA target & T1 & T2 & T3 & T4 & T5 & T6 \\
\hline $\begin{array}{c}\text { mean and SD } \\
\text { hybridization } \\
\text { efficiency } \boldsymbol{\eta} \text { / \% }\end{array}$ & $35 \pm 5$ & $29 \pm 2$ & $15 \pm 2$ & $2 \pm 2$ & $31 \pm 4$ & $18 \pm 2$ \\
\hline $\begin{array}{c}\text { number of } \\
\text { hybridization runs }\end{array}$ & 35 & 3 & 3 & 3 & 4 & 6
\end{tabular}

Table 1. Mean and SD hybridization efficiencies of DNA targets T1 to T6. 
These results indicate that hybridization on a DNA self-assembled monolayer depends on the duplex geometry, due to steric hindrances in the recognition layer. A classic way to overcome this problem is to include a spacer between the transducer surface and the DNA-probe sequence, like PEG [2], neutravidin-biotin complex [19], non complementary DNA sequence [6]. A different approach is herein investigated, consisting of molecular organization of the DNA probe layer by grafting double-stranded DNA.

\section{DNA-biosensor designed by grafting target-probe duplex}

\subsection{Direct grafting of double stranded target-probe duplex on gold surface}

Previous experiments show that both structures of target and probe have an effect on hybridization efficiency, due to repulsion between nucleic acid in the surface vicinity and steric hindrances. To improve hybridization efficiency, a self-assembled monolayer of double stranded probe-target is designed. Target is then removed by circulation of a basic alkaline solution, in order to create a good access to the probe sequence. Different contribution for frequency changes of probe and target are obtained by using a duplex formed with a 20-base DNA probe (P1) and a 40-base DNA target (T5). Microbalance frequency-time curve of P1T5 probe-target duplex grafting, and successive T5 dehybridization-hybridization runs are achieved (Fig. 5).

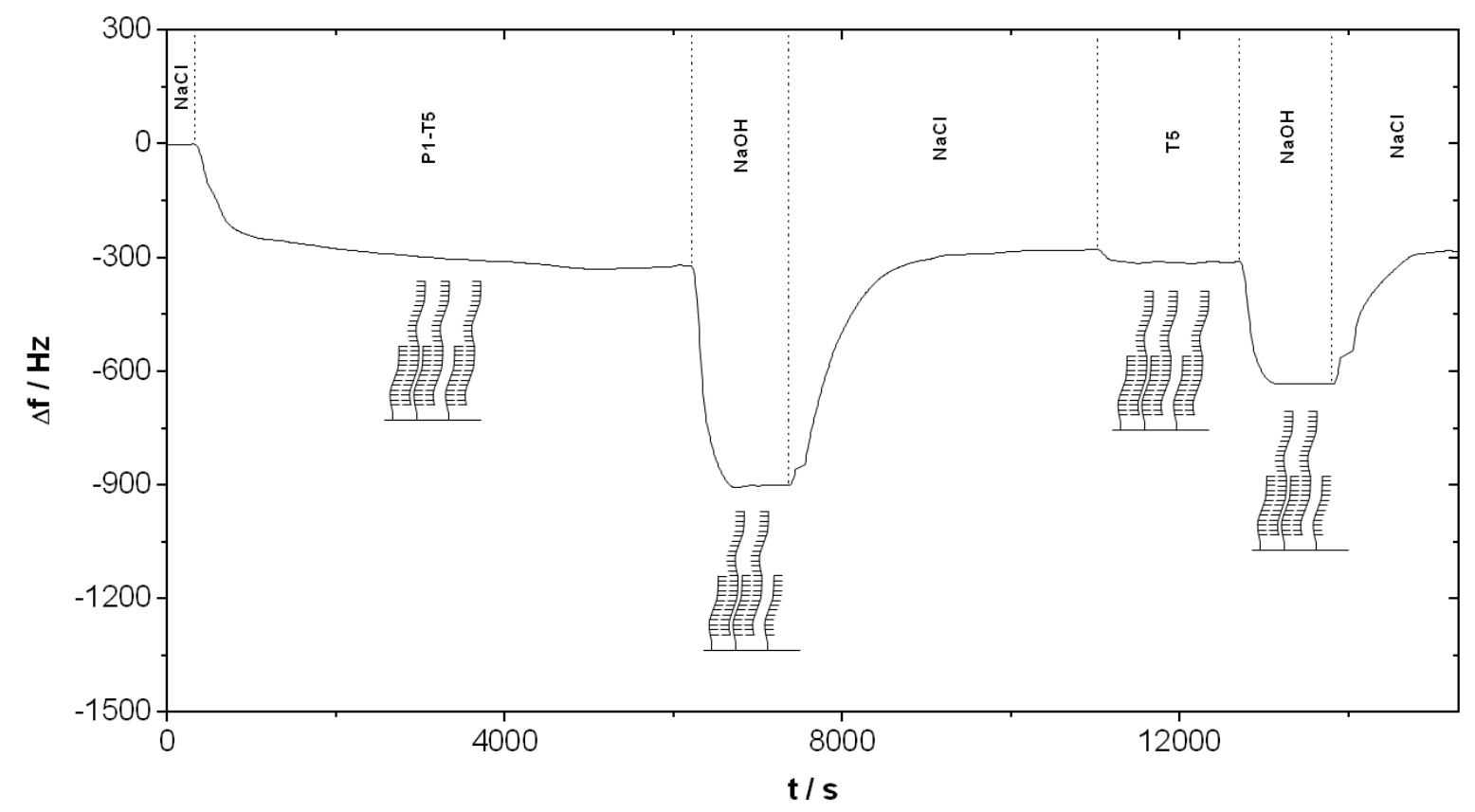

Fig. 5. Frequency-time curves of P1-T5 probe-target duplex grafting and T5 hybridization runs. 
There is a $-327 \mathrm{~Hz}$ microbalance frequency decrease during P1-T5 probe-target duplex grafting. Frequencies changes during successive T5 target dehybridization $(32 \mathrm{~Hz})$, hybridization $(-35 \mathrm{~Hz})$ and dehybridization $(27 \mathrm{~Hz})$ correspond respectively to 15,16 and $12 \%$ hybridization efficiencies. These last values appear low compared to hybridization efficiencies of biosensors designed with self-assembled monolayer of single stranded DNAprobes, close to $40 \%$. If the hypothesis that the $-327 \mathrm{~Hz}$ frequency decrease corresponds to P1-T5 duplex grafting, the estimated microbalance frequency change contribution due to P1 is equal to $-109 \mathrm{~Hz}\left(1.8 .10^{13} \mathrm{probe} / \mathrm{cm}^{2}\right)$ and the frequency change contribution due to $\mathrm{T} 5$ is equal to $-218 \mathrm{~Hz}$, as T5 molecular weight is two times P1 one. So, the frequency change during dehybridization has to be equal to $218 \mathrm{~Hz}$, which is clearly inconsistent with the measured value of $32 \mathrm{~Hz}$. To explain this result, a hypothesis is then formulated: a P1-T5 selfassembled monolayer is formed onto the gold surface, but the DNA are too close from each other, preventing an easy dehybridization. To validate or reject this hypothesis, a new DNAbiosensor is designed in the next trial, by circulation of the same P1-T5 duplex but during a shorter time, in order to avoid formation of a too dense layer, and so to achieve P1-T5 monolayer formation with well spaced probe-target duplex.

\subsection{Shorter grafting step to achieve dilution of double stranded target-probe duplex}

To enable dehybridization, circulation time of the duplex solution is 30 minutes for the grafting step in this case instead of 2 hours previously. Microbalance frequency-time curves of P1-T5 probe-target duplex grafting and successive T5 dehybridization-hybridization runs are performed (Fig. 6). 


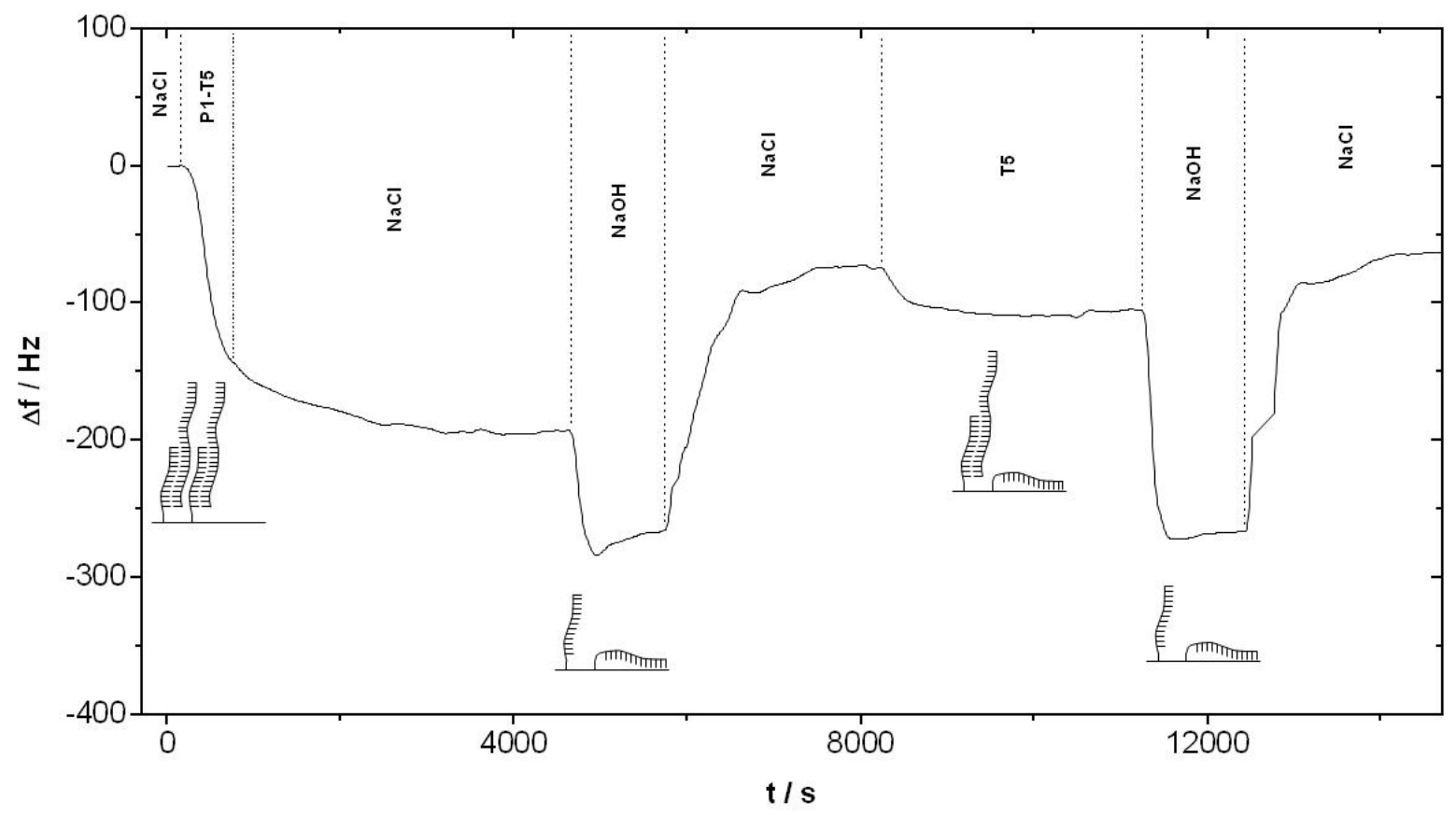

Fig. 6. Frequency-time curves of P1-T5 probe-target duplex grafting (30 min.) and successive T5 dehybridization-hybridization runs.

There is a $-193 \mathrm{~Hz}$ microbalance frequency decrease during P1-T5 duplex grafting. If the hypothesis that this $-193 \mathrm{~Hz}$ frequency decrease corresponds to P1-T5 duplex grafting, the frequency change due to $\mathrm{P} 1$ is equal to $-64 \mathrm{~Hz}\left(1.1 .10^{13}\right.$ probe $\left./ \mathrm{cm}^{2}\right)$ and the frequency change due to T5 is equal to $-129 \mathrm{~Hz}$, as T5 molecular weight is two times P1 one. In these conditions, the frequency change during dehybridization has to be equal to $129 \mathrm{~Hz}$, which is consistent with the measured value of $120 \mathrm{~Hz}$. These results indicate successful P1-T5 duplex grafting and dehybridization in this case. Nevertheless, there is only a $-32 \mathrm{~Hz}$ frequency change during subsequent hybridization of T5 target. Thus, hybridization efficiency is equal to $25 \%$, below the $31 \%$ value for a biosensor designed by grafting single stranded DNA. To explain this result, a new hypothesis is formulated: P1-T5 duplex is firstly grafted on the biosensor surface, T5 is dehybridized during $\mathrm{NaOH}$ circulation, and single stranded well spaced DNA probes lay down onto the gold surface (Fig. 6). Such a phenomenon of thiollabeled probes was previously observed by neutron reflectivity measurements (Levicky et al., 1998) [20]. Lay probes are not available for further hybridization with DNA targets, yielding to the low hybridization efficiency measured. To validate or reject this new scheme, a new biosensor is designed in the next trial by circulation of the same P1-T5 duplex, but using a blocking reagent, in order to prevent probes lay down process onto the gold surface. 
P1-T5 duplex is firstly grafted on the gold covered quartz surface. The biosensor is then immersed in a $10^{-3} \mathrm{M}$ 2-mercapto-1-ethanol solution during 30 minutes under flowing conditions (50 $\mu \mathrm{L} / \mathrm{min})$, in order to avoid the DNA lay-down process previously described. There is a $-186 \mathrm{~Hz}$ frequency decrease during P1-T5 duplex grafting. The frequency change contribution due to $\mathrm{P} 1$ is equal to $-62 \mathrm{~Hz}\left(1.0 .10^{13} \mathrm{probe} / \mathrm{cm}^{2}\right)$ as $\mathrm{T} 5$ molecular weight is two times $\mathrm{P} 1$ one. $\mathrm{T} 5$ is in fine removed by circulation of an alkaline saline solution $(\mathrm{NaOH} 0.5$ $\mathrm{M}, \mathrm{NaCl} 3 \mathrm{M}$ ) during 30 minutes. Successive hybridization and dehybridization runs of complementary targets T5 and T6 targets are achieved (Fig. 7).

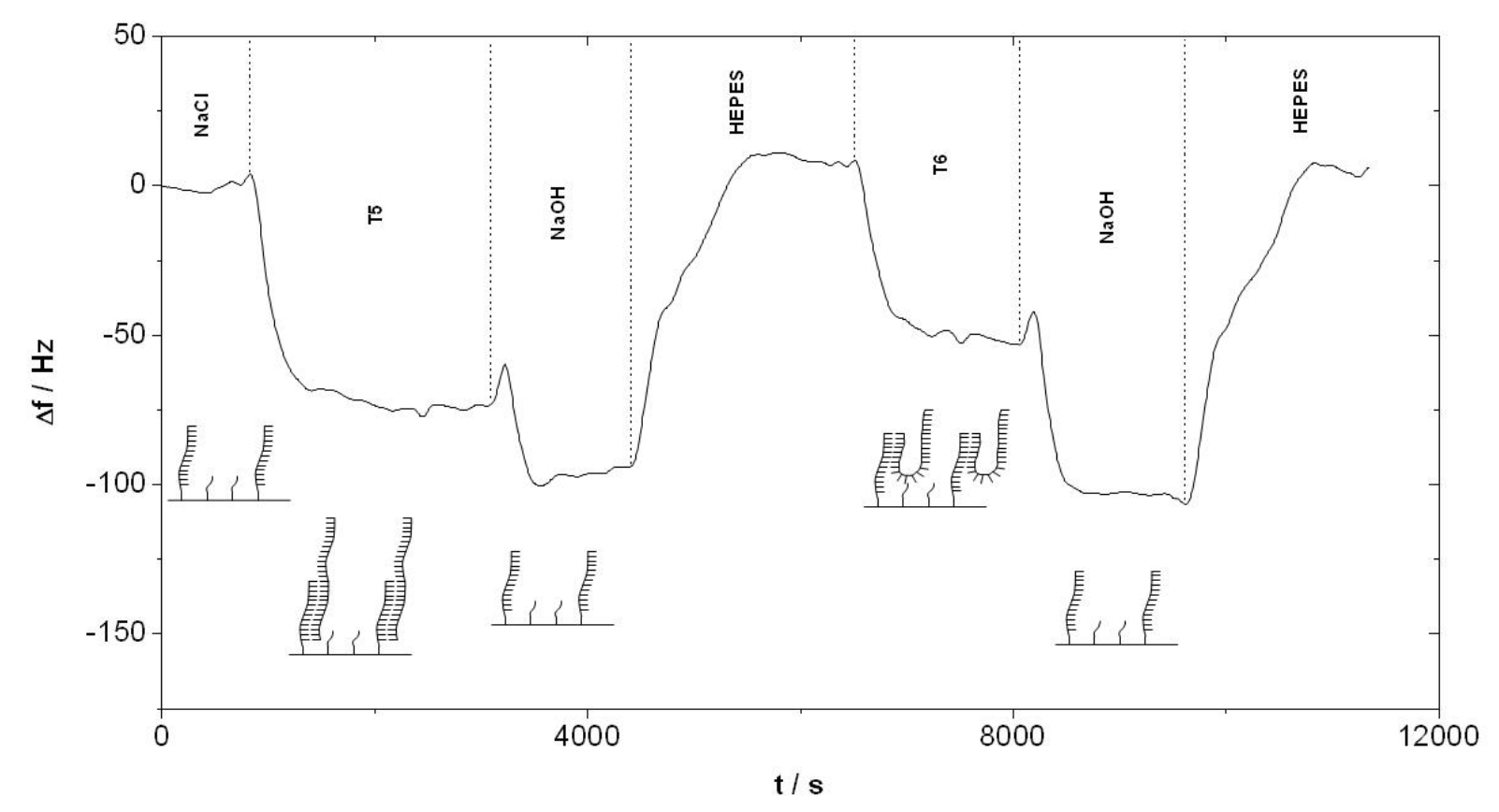

Fig. 7. Biosensor designed by grafting P1-T5 dupex under flowing conditions: frequency-time curve of successive hybridization and dehybridization of T6 and T5 complementary targets.

Frequency decrease during T5 and T6 hybridization are respectively equal to -74 and $-58 \mathrm{~Hz}$, yielding respectively to 60 and $47 \%$ hybridization efficiencies. These hybridization efficiencies are two times higher than those founds with the biosensor designed by a selfassembled DNA probe monolayer, respectively equals to $31 \%$ and $21 \%$ for the same T5 and T6 targets. These results indicate a successful enhancement of hybridization efficiency by grafting double-stranded probe-target duplex and using a blocking reagent in order to avoid the probe lay-down process (Fig. 7). The counterpart of this hybridization efficiency increases, is a decrease of sensitivity: the frequency changes respectively equals to -74 and - 
$58 \mathrm{~Hz}$ for $\mathrm{T} 6$ and $\mathrm{T} 5$ targets is equal to -128 and $-87 \mathrm{~Hz}$ for the biosensor designed with single stranded DNA probes. The blocking reagent conditioning is of prime importance, as it is well known that exchange reaction occurs between thiolated molecules in bulk solution and chemically adsorbed on the surface [21]. In the case of the flowing solution, DNA strands removed from the surface diffuse faster through bulk solution and can not be anymore grafted onto the gold quartz surface, yielding to a lower probe surface density. A last biosensor is designed in the next trial, where the blocking reagent is introduced under batch condition in order to limit desorption kinetics. The experimental protocol is quasi identical. The blocking reagent is in this case introduced onto the gold surface without flow. There is a $-152 \mathrm{~Hz}$ frequency decrease during P1-T5 duplex grafting, the frequency change contribution due to $\mathrm{P} 1$ is equal to $-62 \mathrm{~Hz}\left(8.5 .10^{12}\right.$ probe $\left./ \mathrm{cm}^{2}\right)$. Successive hybridization and dehybridization runs of complementary targets T5 and T6 targets are achieved (Fig. 8).

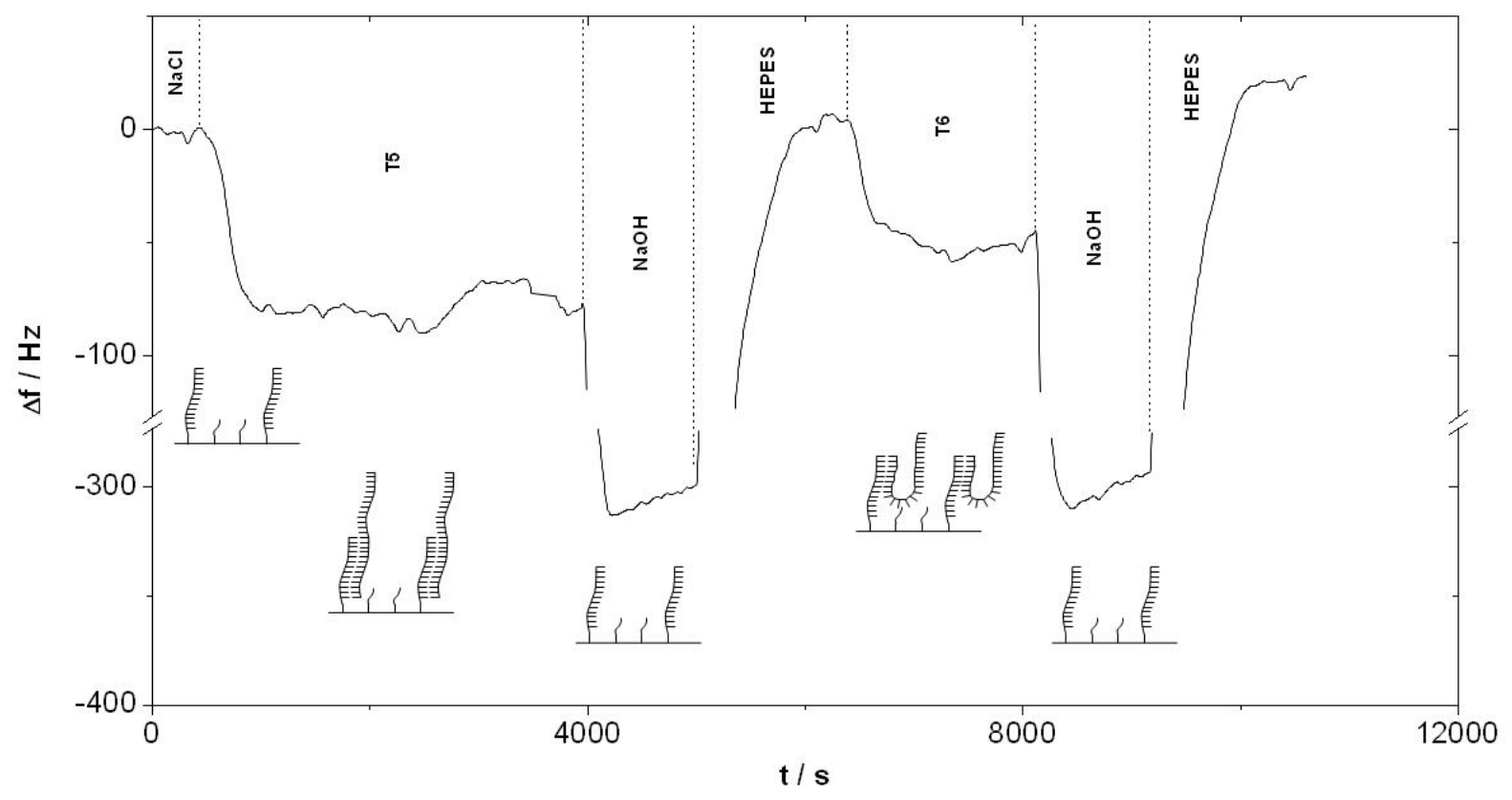

Fig. 8. Biosensor designed by grafting P1-T5 duplex under batch conditions: frequency-time curve of successive hybridization and dehybridization of T6 and T5 complementary targets.

Microbalance frequency decrease during T6 and T5 hybridization are respectively equal to 80 and $-60 \mathrm{~Hz}$, yielding respectively to 79 and 59\% hybridization efficiencies. These hybridization efficiencies are higher than those of the biosensor in which blocking reagent is introduced in the quartz cell under flow, respectively equal to 60 and $47 \%$ for T6 and T5 targets. In batch conditions, the hydrodynamic diffusion layer is larger, resulting in a slower exchange process between grafted probes and 2-mercapto-1-ethanol. 


\section{Comparison of DNA-biosensor behaviors}

Hybridization behaviors of biosensors designed in this study, using single stranded and double stranded probes, are reported Table 2 .

\begin{tabular}{|c|c|c|c|c|c|}
\hline \multicolumn{3}{|c|}{ grafting } & \multicolumn{2}{|c|}{$\begin{array}{c}\text { hybridization efficiency } \eta \\
(\%)\end{array}$} & \\
\hline probe & $\begin{array}{l}\text { blocking } \\
\text { reagent }\end{array}$ & $\begin{array}{c}\text { blocking } \\
\text { reagent flow } \\
\text { rate }\end{array}$ & T5 & T6 & \multirow{5}{*}{ this work } \\
\hline ss P1 & no & na & 31 & 21 & \\
\hline ds P1-T5 & no & na & 25 & na & \\
\hline ds P1-T5 & $\mathrm{HSCH}_{2} \mathrm{CO}_{2} \mathrm{H}$ & $50 \mu \mathrm{L} / \mathrm{min}$ & 60 & 47 & \\
\hline ds P1-T5 & $\mathrm{HSCH}_{2} \mathrm{CO}_{2} \mathrm{H}$ & no & 79 & 59 & \\
\hline Ss-P1 & $\mathrm{HSCH}_{2} \mathrm{CO}_{2} \mathrm{H}$ & no & 68 & 38 & ref. [5] \\
\hline
\end{tabular}

Table 2. Biosensors hybridization efficiencies.

The last protocol established herein yields to a straightforward strategy: it permits to adjust in a one step experiment the spacing between probes, yielding to a high $79 \%$ hybridization ratio for a complementary target and to a 59\% hybridization efficiency for a complementary target including a 20 base non complementary sequence oriented toward the biosensor surface. It is important to note that a $38 \%$ hybridization efficiency of T6 target is reported for a biosensor designed by grafting a single-stranded probe and a blocking reagent under batch conditions [5], clearly below hybridization efficiency measured here with the biosensor designed by grafting double-stranded DNA. This study is one step beyond the first biosensor obtained by grafting a probe-target duplex [1] and permits to equal hybridization efficiency of biosensor mixed SAM architectures including a single stranded probe and a blocking reagent or spacer to optimize probe access [4]. It is in fine complementary to works on biosensors designed with double-stranded DNA in a two-step grafting scheme [7].

\section{Conclusion}

Protocols to design DNA biosensors can not be established by simple analogy with hybridization in bulk solution. Step-by-step design of successive biosensors using doublestranded DNA presented herein, taking into accounts phenomena occurring in an interfacial environment, yields to a straightforward original strategy that enables to design optimised DNA biosensor biolayer in terms of probe accessibility and surface density. 


\section{Acknowledgments:}

We wish to thank the French Ministry of Research for its financial support (ANR PRECODD HABSEACHEAP).

\section{References}

[1] A.W. Peterson, R.J. Heaton, R.M. Georgiadis, The effect of surface probe density on DNA hybridization, Nucleics Acids Research 29 (2001) 5163-5168.

[2] C.X. Zhou, L.Q. Huang, S.F.Y. Li, Microgravimetric DNA sensor based on quartz crystal microbalance: comparison of oligonucleotide immobilization methods and the application in genetic diagnosis, Biosens. Bioelectron. 16 (2001) 85-95.

[3] M. Lazerges, H. Perrot, E. Antoine, A. Defontaine, C. Compere, Oligonucleotide quartz crystal microbalance sensor for the microalgae Alexandrium minutum (Dinophyceae), Biosens. Bioelectron. 21 (2006) 1355-1358.

[4] E.L.S. Wong, E. Chow, J.J. Gooding, DNA recognition interfaces: the influence of interfacial design on the efficiency and kinetics of hybridization, Langmuir 21 (2005) 69576965.

[5] C. Védrine, M. Lazerges, H. Perrot, C. Compère, C. Dreanno, C. Pernelle, How to control accessibility to biosensor probes? Sensor Letters 7 (2009) 952-956.

[6] M. Lazerges, H. Perrot, N. Zeghib, E. Antoine, C. Compere, in-situ QCM DNA-biosensor probe modification, Sensors and Actuators B 100 (2006) 329-337.

[7] J. Razumovitch, K. de França, F. Kehl, M. Wiki, W. Meier, C. Vebert, Optimal hybridization efficiency upon immobilization of oligonucleotide double helices, J Phys Chem B. 18 (2009) 8383-8390.

[8] A. Atsushi, M. Akira, Production of oligonucleotide probe, Patent (1990) 63-19-1087.

[9] Y. Halim, Alexandrium minutum, n. gen. n. sp. dinoflagellé provocant des "eaux rouges", Vie et Milieu 11 (1960) 102-105.

[10] E. Balech, Redescription of Alexandrium minutum Halim (Dinophyceae) type species of the genus Alexandrium, Phycologia 28 (1989) 206-211. 
[11] C. J. Bolch, S.I. Blackburn, J.A. Cannon, G.M. Hallegraeff, The resting cyst of the redtide dinoflagellate Alexandrium minutum (Dinophyceae), Phycologia 30 (1991) 215-219.

[12] M. Campàs, B. Prieto-Simón, J.-L. Marty, Biosensor to detect marine toxins: Assessing seafood safety, Talanta 72 (2007) 884-895.

[13] E. Nezan, C. Belin, P. Lassus, G. Piclet, J.P. Berthome, Alexandrium minutum: first PSP species occurrence in France, Fourth International Conference on Toxic Marine Phytoplankton, Lund, Sweden, 111 (1989).

[14] L. Guillou, E. Nezan, V. Cueff, E. Erard-Le Denn, M.A. Cambon-Bonavita, P. Gentien, G. Barbier, Genetic diversity and molecular detection of three toxic dinoflagellate genera (Alexandrium, Dinophysis, and Karenia) from French coasts, Protist 153 (2002) 223-238.

[15] E. Erard, Recent Approaches on Red Tides, J. S. Park and H. G. Kim Eds 85 (1990).

[16] L. Rodriguez-Pardo, J. Farina, C. Gabrielli, H. Perrot, R. Brendel, Resolution in quartz crystal oscillator circuits for high sensitivity microbalance sensors in damping media, Sensor and Actuator B 103 (2004) 318-324.

[17] K. Bizet, C. Gabrielli, H. Perrot, Immunodetection by Quartz Crystal Microbalance, Applied Biochemistry and Biotechnology 89 (2000) 139-150.

[18] M. Hieda, R. Garcia, M. Dixon, T. Daniel, D. Allara, M.H.W. Chan, Ultrasensitive quartz crystal microbalance with porous gold electrodes, Appl. Phys. Lett. 84 (2004) 628-630.

[19] A. Tsortos, G. Papadakis, K. Mitsakakis, K.A. Melzak, E. Gizeli, Quantitative determination of size and shape of surface-bound DNA using an acoustic wave sensor, Biophysical Journal 94 (2008) 2706-2715.

[20] R. Levicky, T.M. Herne, M.J. Tarlov, S.K. Satija, Using self-assembly to control the structure of DNA monolayers on gold: a neuron reflectivity study, J. Am. Chem. Soc. 120 (1998) 9787-9792.

[21] Y.F. Xing, S.F.Y. Li, A.K.H. Lau, S.J. O'Shea, Electrochemical impedance spectroscopy study of mixed thiol monolayers on gold, Journal of Electroanalytical Chemistry 583 (2005) 124-132. 